\section{Design of dual-band slot antenna with double T-match stubs}

\section{Y.-C. Lin and K.-J. Hung}

A simple and compact design of dual-band slot antenna is presented. Fed by a CPW, the antenna is printed on a single-layer PCB with extremely low manufacturing cost. A pair of T-match stubs is employed to generate the dual resonances in the $2.4-2.5$ and $5-6 \mathrm{GHz}$ bands. The antenna of small radiating area $11 \times 28 \mathrm{~mm}^{2}$ is demonstrated on an FR4 PCB with ground plane size of $31 \times 35 \mathrm{~mm}^{2}$. Robust radiation performances are achieved, including in-band gain flatness within $+/-0.5 \mathrm{~dB}$ and polarisation isolation better than $15 \mathrm{~dB}$. Consistent radiation patterns for both bands are obtained with peak gains about 3 and $4 \mathrm{dBi}$ in the lower and upper bands, respectively.

Introduction: Design of dual-band and multi-band antennas has gained increasing demands in modern wireless communication systems in which the backward compatibility and the roaming capability among multi-standards are required. For instance, the antenna is preferably designed in $2.4-2.5$ and $5-6 \mathrm{GHz}$ bands to meet the standards of IEEE $802.11 \mathrm{a} / \mathrm{b} / \mathrm{g}$ in WLAN systems.

Compared to other transmission line structures, antennas designed with CPW feed have many advantages, including the simple configuration of a single metallic layer, the elimination of complex interconnection with via and solder pads, less coupling with nearby RF components, and ease of integration with active MMIC devices. Hence, the CPW-fed structure is selected and incorporated in the design of the proposed antenna.

In general, the design goals of dual-band antennas in wireless consumer products include low cost, compact size, sufficient impedance bandwidth, high efficiency, omnidirectional patterns, flat gain in the band, low cross-polarisation of radiation patterns, and consistent performances for both bands. Several types of dual-band antenna have been presented in the recent literature, including the monopole with notch [1], the folded monopole [2], and the rectangular aperture [3] and slot loop [4]. However, these antenna designs may satisfy only some of the aforementioned goals while experiencing trade-offs of the others. In this Letter, a robust design of a dual-band slot antenna using double T-match stubs is proposed, aiming to achieve these goals simultaneously.

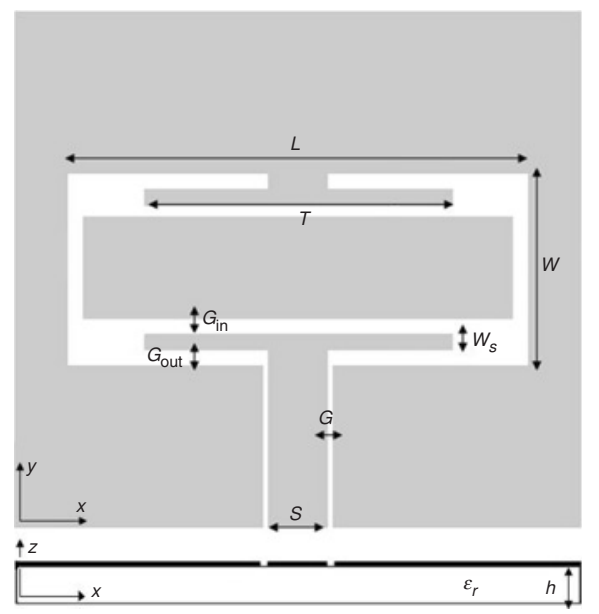

Fig. 1 Antenna geometry

Antenna design: Fig. 1 shows the geometry and configuration of the proposed dual-band slot antenna. The antenna is designed on a singlelayer PCB substrate with dielectric constant $\varepsilon_{r}$, loss tangent tan $\delta$ and thickness $h$. A $50 \Omega \mathrm{CPW}$ transmission line of strip width $S$ and gap $G$ is employed as a feed to the antenna. The open-ended T-match stub of length $T$ and width $W_{s}$ is devised to perform sufficient bandwidth for the input impedance matching $[5,6]$. By adding an extra T-match stub connected to the upper ground, the dual-band resonances of the antenna are generated while keeping good impedance bandwidths and stable radiation characteristics. The effective length of the slot loop is then divided by the T-match pair with the inner circumference designed as $\lambda_{g}$ for the lower-band resonances and the outer circumference about $2 \lambda_{g}$ for the upper-band resonances.
The design of the proposed antenna is performed with a commercial electromagnetic tool [7]. The prototype antenna is illustrated on a low-cost FR4 substrate with dielectric constant $\varepsilon_{r}=4.3$, loss $\tan \delta=0.02$ and thickness $h=1.6 \mathrm{~mm}$. The overall ground plane size of the prototype antenna is $31 \times 35 \mathrm{~mm}^{2}$. The dimensions of other parameters are determined with the optimal performances in terms of the impedance bandwidths and radiation characteristics. The final dimensions are obtained as follows: $S=3.6 \mathrm{~mm}, G=0.4 \mathrm{~mm}, G_{\text {in }}=1 \mathrm{~mm}, G_{\text {out }}=1.25 \mathrm{~mm}, W_{s}=0.5 \mathrm{~mm}$, $T=19 \mathrm{~mm}, L=28 \mathrm{~mm}$, and $W=11 \mathrm{~mm}$.

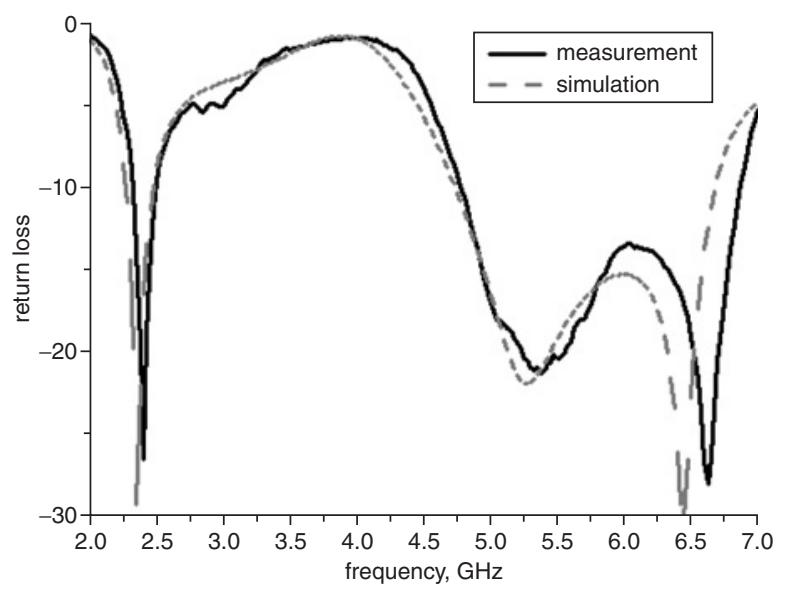

Fig. 2 Measured and simulated return loss of proposed antenna
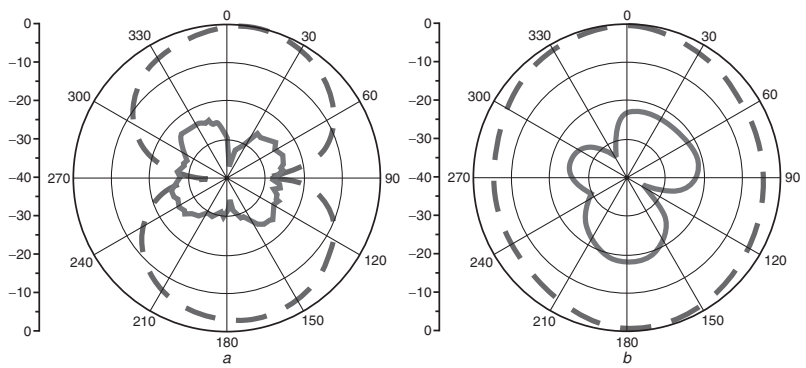

Fig. 3 Measured radiation patterns at $2.45 \mathrm{GHz}$

$a$ E-plane $(y-z$ plane $) \quad b$ H-plane $(x-z$ plane $)$ ----- co-polarisation - cross-polarisation
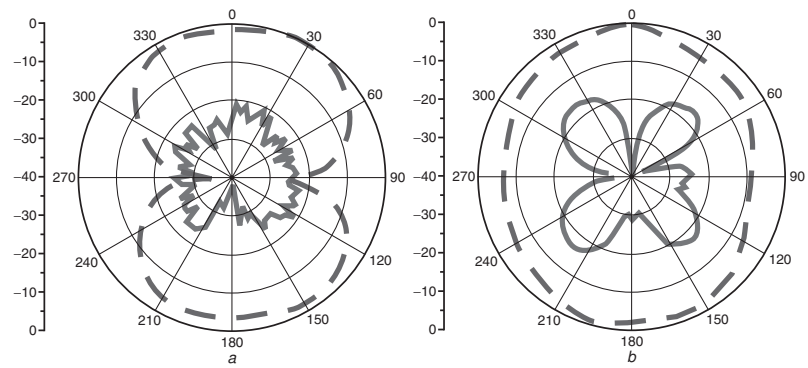

Fig. 4 Measured radiation patterns at $5.2 \mathrm{GHz}$

$a$ E-plane ( $y-z$ plane) $\quad b$ H-plane $(x-z$ plane $)$

----- co-polarisation - cross-polarisation

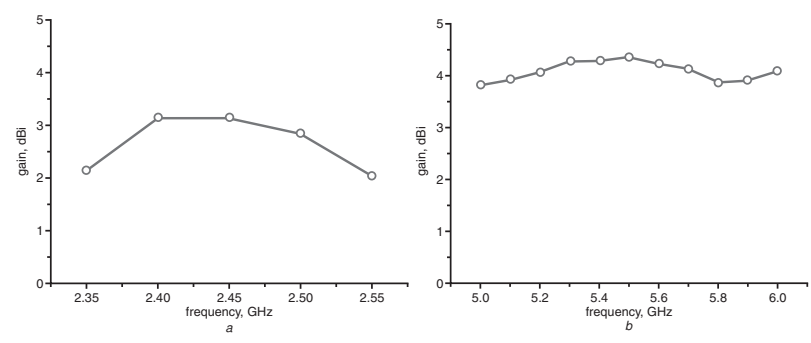

Fig. 5 Measured gain spectrum of proposed antenna a $2.35-2.55 \mathrm{GHz} \quad$ b $5.0-6.0 \mathrm{GHz}$ 
Results and discussion: Fig. 2 shows the simulated and measured input return losses. Good agreement between simulation and measurement results is achieved. The $10 \mathrm{~dB}$ return loss bandwidths are measured from 2.32 to $2.50 \mathrm{GHz}$ in the lower band and 4.78 to $6.85 \mathrm{GHz}$ in the upper band, both exceeding the requirements of IEEE $802.11 \mathrm{a} / \mathrm{b} / \mathrm{g}$ spec. Figs. $3 a$ and $b$ show the normalised radiation patterns of E-plane ( $y-z$ plane) and H-plane ( $x-z$ plane), respectively, measured at $2.45 \mathrm{GHz}$. As expected, the E-plane patterns are bidirectional like a dipole and the H-plane patterns are nearly omnidirectional. It is emphasised that cross-polarisation is significantly suppressed down to the level below $15 \mathrm{~dB}$ in this design, which mainly results from the symmetry of the antenna geometry. Fig. 4 shows the measured radiation patterns at $5.2 \mathrm{GHz}$. Similar to the lower-band performances, the dipole-like patterns and low crosspolarised patterns are achieved, meaning good consistency for both bands. The spectrum of the peak gain is measured as around $3 \mathrm{~dB}$ in the lower band $(2.35-2.55 \mathrm{GHz})$ and $4 \mathrm{~dB}$ in the upper band $(5.0$ $6.0 \mathrm{GHz}$ ), as shown in Figs. $5 a$ and $b$, respectively. The Figures show that the antenna gain is stable and in-band gain flatness is only within $\pm 0.5 \mathrm{~dB}$ for both bands. In practice, the stable in-band antenna gain and consistent gain patterns in the two operation bands are desired in real applications of dual-band WLAN systems.

Conclusions: A dual-band CPW-fed slot antenna has been designed, built and measured. The proposed antenna performs the exceeding impedance bandwidths and stable antenna gains in both bands. Using the symmetric double T-match stubs as feeding structures, the design may significantly suppress the cross-polarisation level, a common problem existing in dual-band antenna design. The proposed antenna is cost-effective, simple, compact, and the dual-band design has stable gain and low cross-polarisation in both bands. These features make the proposed antenna robust and suitable for applications of any dualband wireless communication system.
Acknowledgment: This work was supported in part by the National Science Council (NSC), Taiwan, under contract nos NSC 94-2219-E002-007 and NSC 94-2752-E-002-002-PAE.

(C) Institution of Engineering and Technology 2006

2 January 2006

Electronics Letters online no: 20060009

doi: 10.1049/el:20060009

Y.-C. Lin (Department of Electrical Engineering and Graduate Institute of Communication Engineering, National Taiwan University, Taipei, Taiwan, Republic of China)

E-mail: yclin@cc.ee.ntu.edu.tw

K.-J. Hung (Graduate Institute of Communication Engineering, National Taiwan University, Taipei, Taiwan, Republic of China)

\section{References}

1 Liu, W.-C., and Wu, C.-M.: 'Broadband dual-frequency CPW-fed planar monopole antenna with rectangular notch', Electron. Lett., 2004, 40, (11), pp. $642-643$

2 Lin, Y.-D., and Chi, P.-L.: 'Tapered bent folded monopole for dual-band wireless local area network (WLAN) systems', IEEE Antennas Wirel. Propag. Lett., 2005, 4, pp. 355-357

3 Wu, J.-W., et al.: 'Dual broadband design of rectangular slot antenna for 2.4 and $5 \mathrm{GHz}$ wireless communication', Electron. Lett., 2004, 40, (23), pp. 1461-1463

4 Llorens, D., Otero, P., and Camacho-Penalosa, C.: 'Dual-band, single CPW port, planar-slot antenna', IEEE Trans. Antennas Propag., 2003, 51, (1), pp. 137-139

5 Balanis, C.A.: 'Antenna theory and design' (Wiley, New York, 1997, 2nd edn.)

6 Perruisseau-Carrier, J., del Río, D.L., and Mosig, J.R.: 'A new integrated match for CPW-FED slot antennas', Microw. Opt. Technol. Lett., 2004, 42, (6), pp. 444-448

7 Ansoft HFSS version 9.2 